\title{
Lesión lítica en el Radio distal
}

\author{
Fernando Hidalgo Méndez ${ }^{\mathrm{a}}$
}

\begin{abstract}
a Médico especialista en Diagnóstico por la Imagen, Servicio de Diagnóstico por la Imagen, CAP EI Serral (Institut Català de la Salut), Sant Vicenç dels Horts, Barcelona.
\end{abstract}

Correspondencia: Fernando Hidalgo Méndez, SDPI, CAP EI Serral, Carretera de Sant Boi, 59-61, 08620-Sant Vicenç dels Horts, Barcelona, España. Telf.: 936724859, fax: 936724796, correo electrónico: 26415fhm@comb.cat.

Recibido el 19 de octubre de 2011.

Aceptado para su publicación el 4 de noviembre de 2011.

\begin{abstract}
RESUMEN
El tumor de células gigantes de hueso es una neoplasia controvertida. En la mayoría de los casos se comporta como un tumor benigno, pero aproximadamente un $15 \%$ de ellos se considerarán malignos durante su evolución. En una fase inicial, la malignidad no puede determinarse ni por el aspecto radiológico ni incluso tampoco después de un estudio histopatológico, sino que será la tasa de recurrencias (si ello ocurre) la que indicará la malignidad.

En este artículo se presenta el caso de un paciente varón de 47 años con una lesión sospechosa en el radio distal y definimos los signos radiológicos que sugerirán un diagnóstico por imagen de un tumor óseo de células gigantes.
\end{abstract}

Palabras Clave. Neoplasias Óseas. Células Gigantes

\section{ABSTRACT}

Bone lesion in the distal radius

Giant cell tumor of the bone is a controversial neoplasm. In most cases, it behaves as a benign tumor, but approximately $15 \%$ of cases will be diagnosed as malignant during the clinical course. In the initial phase, malignancy cannot be determined neither by radiological appearance nor by histopathology; instead, recurrences of the tumor will most consistently indicate malignancy. In this report, we present the case of a 47 year old male patient with a suspicious lesion in the distal radius and we define the radiological signs that suggest diagnosis of giant cell tumor of the bone.

Key words. Bone Neoplasms, Giant Cells.

\section{INTRODUCCIÓN}

El tumor de células gigantes (TCG) óseo es una lesión benigna que representa entre un 15 y un $20 \%$ de las neoplasias benignas óseas ${ }^{1,2}$ y alrededor de un $5 \%$ del total de los tumores óseos ${ }^{3}$. Se localiza típicamente en la metáfisis y la epífisis de los huesos largos. En un $50 \%$ de los casos afectará a los huesos largos de la articulación de la rodilla y, con menor frecuencia, puede observarse en el fémur proximal, tibia distal, radio distal y húmero proximal|3.4. Raramente afecta a huesos planos como el sacro o la pelvis ${ }^{3} \mathrm{o}$ a los huesos de manos y pies ${ }^{4,5}$. Ocurre principalmente entre los 20 y los 45 años de edad $^{3,4}$, siendo inhabitual en personas con el esqueleto inmaduro. En alguna serie $^{3}$ se ha descrito una mayor prevalencia en mujeres (3:1).

Aunque se trata de una lesión en principio benigna, presenta una tendencia a la recidiva local tras el tratamiento inicial ${ }^{1,3,4,6}$. Existe también la posibilidad de metástasis a distancia, principalmente a pulmón (en un $2 \%$ de los casos después de 3 a 4 años del diagnóstico inicial), así como a ganglios linfáticos regionales, mediastino, piel, cuero cabelludo y pelvis ${ }^{1,4}$. Se trata, por tanto, de una lesión controvertida al tener un comportamiento difícil de predecir, no siendo posible descartar un potencial futuro maligno ni en base a los hallazgos radiológicos iniciales ni a su histología, considerándose que hasta un $15 \%$ de los casos de TCG óseo serán malignos en base a su tasa de recurrencias ${ }^{7}$.

\section{OBSERVACIONES CLÍNICAS}

Paciente varón de 47 años de edad, sin antecedentes patológicos de interés, que consulta por notar desde hace unos meses dolor e hinchazón en la muñeca derecha. 
La exploración física general y una analítica general no presentan alteraciones significativas. La exploración física de la muñeca derecha constata la existencia de dolor y de tumefacción a ese nivel. La radiografía simple de la zona (figura 1) muestra la presencia de una lesión lítica epifisaria a nivel del radio distal, excéntrica con respecto al eje longitudinal del hueso, que no rompe la cortical ósea y tiene bordes bien definidos en gran parte de su contorno, llegando a estar dicha lesión en contacto con la superficie articular radiocarpiana.

Se realiza una biopsia guiada por TC, que establece el diagnóstico anátomo-patológico de un tumor óseo de células gigantes. Se interviene quirúrgicamente realizando un legrado y un relleno con cemento y sustituto óseo (fostato de calcio). La evolución postquirúrgica es satisfactoria y el paciente permanece libre de recidiva hasta la fecha actual.

\section{COMENTARIOS}

Dentro del grupo de los tumores óseos, el TCG constituye una entidad controvertida. Este hecho radica en dos aspectos: en la necesidad de disponer de unos criterios claros en el diagnóstico mediante radiología simple que nos permitan diferenciarlo de otras lesiones óseas de características parcialmente superponibles; y en la dificultad de aseverar en la fase inicial de su diagnóstico cuál será su comportamiento futuro, siendo éste benigno en la mayoría de los casos (pero con una evolución maligna que puede cifrarse hasta en un $15 \%$ de estas lesiones ${ }^{7}$ ).

EI TCG representa entre un 15 y un $20 \%$ de las lesiones tumorales óseas benignas ${ }^{1,2}$. Se localiza principalmente en la metáfisis y la epífisis de huesos $\operatorname{largos}^{3,4}$ (sobre todo en los que intervienen en la articulación de la rodilla), siendo poco frecuente en otras localizaciones tales como los huesos cortos de manos y pies o los huesos planos ${ }^{3,4,5}$. La edad típica de presentación suele estar entre los 20 y los 45 años de edad ${ }^{3,4}$, habiendo sido descrita una mayor prevalencia femenina ${ }^{3}$. Rara vez es múltiple ${ }^{3}$. El síntoma más frecuente de presentación suele ser el dolor local, siendo más infrecuentes la deformidad ósea y la disfunción mecánica osteoarticular ${ }^{3}$.

Desde el punto de vista histológico, presenta un componente bifásico de células gigantes multinucleadas y otro fusocelular muy vascularizado ${ }^{3,4}$. Este patrón hace que el patólogo deba barajar un amplio número de posibilidades en el diagnóstico diferencial ${ }^{4}$, siendo además imposible de prever si un TCG óseo va a desarrollar o no una evolución maligna (con recurrencias locales e, incluso, con metástasis a distancia) basándonos sólo en el aspecto histopatológico ${ }^{3,7}$.

En esta comunicación se pretende hacer especial énfasis en el diagnóstico por imagen de este tipo de lesiones mediante la radiología ósea simple, que será la primera prueba de la que dispondremos habitualmente en el ámbito de la asistencia médica primaria. Radiológicamente no será posible predecir (de manera similar a lo que sucede con el diagnóstico histopatológico) si un TCG óseo tendrá una evolución benigna o presentará complicaciones. Pero sí será de enorme utilidad conocer un grupo de cuatro criterios radiológicos que, cuando coinciden todos a la vez, nos indican que nos hallamos ante este tipo de neoplasia y nos permiten establecer ya, en una fase inicial del proceso y con muy poco margen de error, el diagnóstico radiológico de TCG de hueso. Estos cuatro criterios radiológicos son $^{7}$ : 1. EI TCG óseo aparece en pacientes con las epífisis cerradas; 2. La lesión debe ser epifisaria y lindar con la superficie articular; 3 . Presenta una localización excéntrica (y no central) en el hueso; 4. La zona de transición de la lesión con respecto al hueso adyacente normal debe ser estrecha y bien definida, pero no esclerótica (los huesos planos y el calcáneo serían dos excepciones a este último criterio).

El caso aquí presentado corresponde a un varón de 47 años en el que se cumplían simultáneamente (condición ésta sine qua non para el diagnóstico radiológico de TCG óseo) los cuatro criterios radiológicos descritos (figura 1). Este diagnóstico fue confirmado mediante una biopsia guiada por tomografía computerizada. La actitud terapéutica consistió en un legrado de la lesión y un relleno con cemento y sustituto óseo (fostato de calcio). Un año después, el paciente no presenta signos de recidiva local ni de afectación metastásica.

Se puede concluir afirmando que el caso aquí descrito nos es útil, tanto a los especialistas de Medicina de Familia y Comunitaria como a los de Diagnóstico por la Imagen, para conocer mejor los signos clínico-radiológicos con lo que se presenta este no del todo infrecuente y a la vez controvertido tumor óseo benigno, para llegar a un diagnóstico de sospecha en el menor tiempo posible y para persistir en alerta una vez acabado el tratamiento inicial, dada la posibilidad de un ulterior comportamiento maligno (imposible de prever ni por la histología ni 
por la imagen radiológica en una fase inicial, y sólo constatable si posteriormente la lesión recidiva de manera local y/o presenta afectación metastásica a distancia)

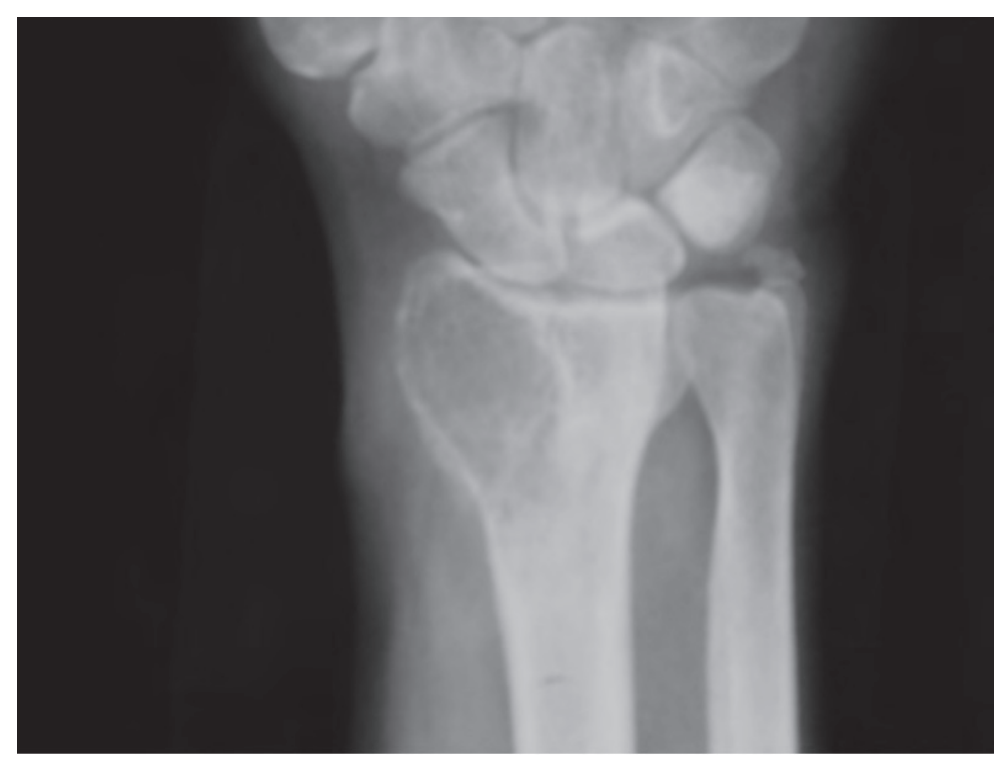

Figura 1. Imagen radiológica de una lesión lítica epifisaria a nivel del radio distal.

\section{BIBLIOGRAFÍA}

1. Aflab K, Umar B. Giant cell tumor of bone with lymph node metastases: A rare presentation. Indian J Pathol Microbiol. 2011; 54:396-7.

2. Yüceturk G, Sabah D, Keçeci B, Kara AD, Yalçinkaya S. Prevalence of bone and soft tissue tumors. Acta Orthop Traumatol Turc. 2011; 45:135-43.

3. De la Garza NJM, Ceccopieri CA, Cruz H, Díaz LR, Martínez R. Tumor de células gigantes de hueso. Aspectos generales de 11 casos. Rev Med Hosp Gen Mex. 1999; 62:240-4.

4. Martínez-Tello FJ, Manjón P, Montes S (2005, octubre). Diagnóstico diferencial de las lesiones de células gigantes de hueso. Ponencia presentada en el VII Congreso Virtual
Hispanoamericano de Anatomía Patológica y I Congreso de Preaparaciones Virtuales por Internet.

5. Saikia KC, Bhuyan SK, Ahmed F, Chanda D. Giant cell tumor of the metacarpal bones. Indian J Orthop 2011; 45:475-8.

6. Saikia KC, Bhattacharyya TD, Bhuyan SK, Bordoloi B, Durgia B, Ahmed F. Local recurrences after curettage and cementing in long bone giant cell tumor. Indian J Orthop. 2011; 45:168-73.

7. Helms CA. Lesiones líticas benignas. En: Helms CA, editor. Fundamentos de radiología del esqueleto. $1^{a}$ ed. española. Madrid: Editorial Marbán; 1993. p. 9-40. 